\title{
The evaluation of glutathione concentration in whole blood of Holstein dairy calves
}

\author{
A. Nečasová ${ }^{1}$, A. Pechová ${ }^{1}$, R. Bodor ${ }^{2}$, M. Masár ${ }^{2}$, M. Holasová ${ }^{1}$ \\ ${ }^{1}$ University of Veterinary and Pharmaceutical Sciences Brno, Faculty of Veterinary Hygiene and Ecology, \\ Department of Animal Protection, Welfare and Behaviour, Brno, Czech Republic \\ ${ }^{2}$ Comenius University Bratislava, Faculty of Natural Sciences, Department of Analytical Chemistry, \\ Bratislava, Slovakia \\ Received February 4, 2019 \\ Accepted April 23, 2019
}

\begin{abstract}
The aim of this study was to evaluate the concentrations of total (T-GSH), oxidized (GSSG) and reduced glutathione (GSH) in blood of clinically healthy calves, to assess the effect of sex and age together with the type of feeding on its concentrations, and to assess the relationships between glutathione and metabolic indices. A total of 117 Holstein calves at the age of 1 day to 6 months were divided according to age and together with the type of feeding into 4 groups: colostrum and transition milk $(n=20)$, native milk $(n=39)$, milk replacer $(n=29)$ and total mixed ration $(n=29)$. Blood serum was used for the assessment of the metabolic profile of calves. The concentrations of individual forms of glutathione (mean \pm SEM) were as follows: T-GSH: 789.1 $\pm 19.4 \mu \mathrm{mol} / 1$, GSSG: $54.2 \pm 4.3 \mu \mathrm{mol} / 1$, GSH: $681.6 \pm 15.3 \mu \mathrm{mol} / 1$, and GSH/GSSG: $41.1 \pm 5.9$, with the coefficients of variability of $26.6 \%, 85.3 \%, 24.3 \%$ and $157.4 \%$, respectively. Age and the type of feeding affected GSSG $(P \leq 0.01)$ and GSH/GSSG $(P \leq 0.01)$. The relationships between glutathione and biochemical parameters were mostly weak. T-GSH correlated with creatinine $(P \leq 0.05)$ and chlorides $(P \leq 0.05)$; GSSG correlated with albumin $(P \leq 0.01)$, creatinine $(P \leq 0.01)$, cholesterol $(P \leq 0.05)$, aspartate aminotransferase $(P \leq 0.01)$, alanine aminotransferase $(P \leq 0.01)$, gamma-glutamyltransferase $(P \leq 0.05)$ and calcium $(P \leq 0.05)$; GSH/GSSG ratio correlated with creatinine $(P \leq 0.01)$, cholesterol $(P \leq 0.05)$, aspartate aminotransferase $(P \leq 0.05)$, gamma-glutamyltransferase $(P \leq 0.01)$ and calcium $(P \leq 0.05)$. The evaluation of individual forms of glutathione helps in estimation of redox status in healthy animals and their monitoring can detect the stress extent.
\end{abstract}

GSH, GSSG, GSH/GSSG, dairy cattle, age with feeding, sex, metabolic profile

Glutathione is the most abundant low molecular weight thiol compound. During the evolution, glutathione has adapted to perform many diverse functions. It mainly protects cells from the toxic effects of reactive oxygen compounds.

In physiological conditions and redox homeostasis, most of the glutathione occurs as reduced glutathione (GSH); oxidized glutathione (GSSG) levels range approximately one to two orders of magnitude lower. Reduced glutathione serves as a reducing agent that enables the biological function in free radical defensive mechanisms. Both GSH and GSSG can rise upon stress factors. It is believed that the GSH/GSSG ratio reflects the amount of stress caused by the growth of free radicals in organism. Disruption of glutathione homeostasis gives rise to reactive oxygen species (ROS).

Reduced glutathione is found in the cytosol of cells ranging between 1-10 mmol/1 (Meister 1988). Levels of GSH in plasma are only of $2 \%$ compared to those inside the cell. Inside the cell, glutathione can be found in cytoplasm, mitochondria, and ribosomes. Once GSH is formed by the cell, it is retained inside for the cell's needs and only GSSG can be transported via the cell membrane into the extracellular space. Oxidized glutathione is potentially toxic to the cell but especially high glutathione reductase activity is adequate enough for regeneration of GSH. Its availability in the reduced form may be a key factor in the maintenance of health (Rossi et al. 2002). Several animal and human models 
have shown that a decrease in GSH concentrations can be associated with ageing and the pathogenesis of many diseases (Rossi et al. 2002).

Several methods for glutathione determination were described in the past. Only a few of them have survived over time and are suitable for measurements nowadays. Basically, spectrophotometry- and HPLC-based methods and capillary electrophoresis are the only options that have replaced the many methods used for glutathione determination in the past (Rossi et al. 2002). Spectrophotometrically, GSH and GSSG can be measured as a recycling assay or as an endpoint determination. This method is quick, simple and suitable for the assessment of glutathione in blood samples. The preanalytical phase does not require difficult sample preparation. The -SH group of GSH is immediately blocked by adding a stabilizing agent into the sample right after its withdrawal and therefore this method is suitable for the use in outdoor conditions and transport without overestimation of GSSG levels. HPLC-based methods are capable of detecting GSH and GSSG of very low picomolar concentrations and with high specifity. On the other hand, all of the HPLC-based methods require sample derivatization and usually deproteination (Rossi et al. 2002). Electrochemical separation by isotachophoresis (ITP) seems to be another suitable method. It enables specific determination of both GSH and GSSG in the same sample at the same time (Bodor et al. 2018). Nevertheless, no standard method of glutathione assessment exists and even discrepancies in sample preparation and units of GSH and GSSG levels aggravate the comparison of results among individual experiments.

The main aim of our study was to evaluate the concentration of total glutathione (T-GSH), GSSG, GSH and the GSH/GSSG ratio in blood of dairy calves, and to assess the effect of sex, age, and the type of feeding on its concentrations. The other aim was to assess the relationships between individual forms of glutathione to the concentration of haemoglobin $(\mathrm{Hb})$ and selected indices of metabolic profile in calves.

\section{Materials and Methods}

Animals

In total, 117 calves of Holstein cattle were involved in our study. The calves came from one dairy farm in the region of South Moravia and were selected based on their sex, age, and together with the type of feeding and stabling. The sample collection was performed during the autumn and winter seasons of 2016 and 2017. Consequently, the animals were divided into four groups (Group CM, Group M, Group MR, and Group TMR). Group CM $(n=20)$ consisted of calves at the age of 1 to 5 days after birth, fed with colostrum and transition milk; Group M $(n=39)$ involved animals at the age of 6 to 14 days and fed with fresh milk; Group MR $(n=29)$ consisted of calves at the age of 15 days to 2.5 months, all fed with milk replacer by means of an automatic milk feeding machine. The last Group TMR $(n=29)$ comprised calves at the age of 4 to 6 months, fed with the total mixed ration (TMR) completed with the starter mixture.

Calves in Group CM were stabled individually on deep bedding in an indoor cowshed part and they were fed twice a day at 7:00 $\mathrm{h}$ and after 14:00 $\mathrm{h}$ with at least 2 litres of fresh colostrum or transition milk. The first feeding was done within $3 \mathrm{~h}$ after birth with at least 2 litres of first colostrum. Calves older than 5 days (Group M) were stalled in individual outdoor boxes and were fed with fresh milk two times a day, receiving 3 litres of native fresh milk. The starter (CALVES 1 RATIBOR NON GMO, VK-DRCMAN s.r.o. Němčice, Kostelec u Holešova, Czech Republic) was offered from the age of 6 days, all calves had access to fresh water during the whole day.

Calves in Group MR were stabled in groups of approximately 10 animals on deep bedding. Each calf was fed twice to three times a day by an automatic feeding machine with approximately 6 litres of milk replacer per day (TEKRO BRILLANT CALF CARE, Josera GmbH, Kleinheubach, Germany) according to their weight and age. Hay, straw and starter pellet mixture (CALVES OLD, VK-DRCMAN s.r.o. Němčice, Kostelec u Holešova, Czech Republic) was available ad libitum. The compositions of the milk replacer and starter are shown in Tables 1-3.

Animals in Group TMR were associated in larger groups of approximately 25 animals. Calves were fed with the TMR (Table 4) and starter pellet mixture (CALVES OLD, VK-DRCMAN s.r.o. Němčice, Kostelec u Holešova, Czech Republic) two times a day at an approximate amount of $1 \mathrm{~kg}$ per day. The housing for animals in Group MR and TMR was opened from the front part. Fresh water was available for all the animals.

\section{Sampling procedure}

Blood was taken as part of a general health check-up of the herd for preventive diagnostic purposes. All animals involved in the study were clinically examined by checking respiratory rate, heart rate, body temperature, hydration status, and colour of mucosa. Only healthy individuals were involved in this study. 
Table 1. The content of nutrients in milk replacer (TEKRO BRILLANT CALF CARE).

\begin{tabular}{lccc}
\hline Analytical components & \multicolumn{3}{c}{ Additional nutrients in 1 kg } \\
\hline Crude protein & $22 \%$ & Vitamin A & $25000 \mathrm{IU}$ \\
Crude fibre & $0.04 \%$ & Vitamin E & $150 \mathrm{mg}$ \\
Crude oils and fats & $18 \%$ & Copper & $8 \mathrm{mg}$ \\
Crude ash & $8.2 \%$ & Iron & $100 \mathrm{mg}$ \\
Calcium & $0.9 \%$ & Manganese & $70 \mathrm{mg}$ \\
Phosphorus & $0.75 \%$ & Zinc & $80 \mathrm{mg}$ \\
Sodium chloride & $0.75 \%$ & Iodine & $1 \mathrm{mg}$ \\
Lysine & $1.9 \%$ & Selenium & $0.4 \mathrm{mg}$ \\
\hline
\end{tabular}

Table 2. The content of nutrients in starter (CALVES 1 RATIBOR NON GMO).

\begin{tabular}{lccc}
\hline Analytical components & \multicolumn{3}{c}{ Additional nutrients in 1 kg } \\
\hline Crude protein & $18.6 \%$ & Vitamin A & $12000 \mathrm{IU}$ \\
Crude fibre & $7.3 \%$ & Vitamin D3 & $1200 \mathrm{IU}$ \\
Crude oils and fats & $3.4 \%$ & Copper & $13 \mathrm{mg}$ \\
Crude ash & $7.2 \%$ & Iron & $37 \mathrm{mg}$ \\
Calcium & $1 \%$ & Manganese & $42 \mathrm{mg}$ \\
Phosphorus & $0.5 \%$ & Zinc & $56 \mathrm{mg}$ \\
Sodium chloride & $0.3 \%$ & Iodine & $1.1 \mathrm{mg}$ \\
Magnesium & $0.2 \%$ & Selenium & $0.2 \mathrm{mg}$ \\
\hline
\end{tabular}

Table 3. The content of nutrients in starter (CALVES OLD).

\begin{tabular}{lrll}
\hline Analytical components & \multicolumn{3}{c}{ Additional nutrients in $1 \mathrm{~kg}$} \\
\hline Crude protein & $17.6 \%$ & Vitamin A & $8000 \mathrm{IU}$ \\
Crude fibre & $7.3 \%$ & Vitamin D3 & $800 \mathrm{IU}$ \\
Crude oils and fats & $2.7 \%$ & Copper & $8.8 \mathrm{mg}$ \\
Crude ash & $7.2 \%$ & Iron & $25 \mathrm{mg}$ \\
Calcium carbonate & $1.0 \%$ & Manganese & $28 \mathrm{mg}$ \\
Phosphorus & $0.7 \%$ & Zinc & $37 \mathrm{mg}$ \\
Sodium chloride & $0.2 \%$ & Iodine & $0.8 \mathrm{mg}$ \\
Magnesium & $0.2 \%$ & Selenium & $0.1 \mathrm{mg}$ \\
\hline
\end{tabular}

Table 4. The content of nutrients in total mixed ration.

\begin{tabular}{lccc}
\hline & \multicolumn{2}{c}{ Analytical components in kg of dry matter } \\
\hline Crude protein & $161.5 \mathrm{~g}$ & Vitamin A & $12290 \mathrm{IU}$ \\
NEL & $6.8 \mathrm{MJ}$ & Vitamin D3 & $2230 \mathrm{IU}$ \\
Crude fibre & $163.7 \mathrm{~g}$ & Vitamin E & $32 \mathrm{mg}$ \\
Starch & $246.6 \mathrm{~g}$ & Copper & $19.22 \mathrm{mg}$ \\
Fat & $45.7 \mathrm{~g}$ & Zinc & $81.10 \mathrm{mg}$ \\
Calcium & $9.8 \mathrm{~g}$ & Iodine & $1.16 \mathrm{mg}$ \\
Phosphorus & $4.8 \mathrm{~g}$ & Selenium & $0.39 \mathrm{mg}$ \\
Magnesium & $3.3 \mathrm{~g}$ & & \\
\hline
\end{tabular}


The blood was obtained by venipuncture of v. jugularis into two Hemos tubes (Gama Group a. s., České Budějovice, Czech Republic) after the morning feeding. Blood from the first tube was used for obtaining serum for biochemical analysis. The blood was kept at the room temperature and after coagulation the serum was harvested by centrifugation at $2000 \mathrm{~g}$ for $15 \mathrm{~min}$ (Jouan B4i cetrifuge, Trigon Plus s.r.o, Čestlice, Czech Republic). Blood from the second tube was promptly transferred into Vacutainer tubes with ethylenediaminetetraacetic acid tripotassium salt (K EDTA) as antiocoagulant (Greiner Bio-One, Kremsmünster, Austria) for later assessment of $\mathrm{Hb}$ concentration. Consequently, 50 and $100 \mu \mathrm{l}$ of $\mathrm{K}_{3}$ EDTA-treated blood were placed into Eppendorf tubes; the latter with a 10- $\mu$ l content of scavenger 1-methyl-2-vinyl-pyridium trifluoromethanesulphonate (M2VP) for determination of total GSH and GSSG, respectively. Part of the $\mathrm{K}_{3}$ EDTA treated blood was pipetted into sodium fluoride tubes for the assessment of glucose. According to Bioxytech GSH/GSSG-412 kit (Portland, USA) instructions, the blood was immediately placed on ice and after transportation, samples were stored at $-70^{\circ} \mathrm{C}$ until the next day. Serum was stored at $-20^{\circ} \mathrm{C}$ and samples for the analysis of $\mathrm{Hb}$ concentration at $4{ }^{\circ} \mathrm{C}$ until analysed.

\section{Analytical procedure}

All laboratory analyses were performed at the Department of Animal Protection, Welfare and Behaviour of the University of Veterinary and Pharmaceutical Sciences Brno.

Concentrations of T-GSH, GSH, GSSG and $\mathrm{Hb}$ was determined in whole blood. Other biochemical indices were measured in blood serum with the exception of glucose (Glu) which was measured in fluoride plasma. We monitored the following biochemical indices in serum: total protein (TP), albumin (Alb), total bilirubin (Tbil), urea (U), creatinine (Crea), cholesterol (Chol), triacylglycerols (TAG), aspartate aminotransferase (AST), alkaline phosphatase (ALP), alanine aminotransferase (ALT), gamma-glutamyltransferase (GGT), calcium (Ca), inorganic phosphorus (P) and chlorides (Cl).

The glutathione concentration was assessed by the commercial photometric assay Bioxytech GSH/GSSG412 (Oxis International, Inc., Portland, USA) with the use of Varioskan Flash spectrophotometric analyser (Thermo Fischer Scientific, Waltham, USA). In principle, the procedure was based on the Ellman's method using the spectrophotometric assessment of the colour complex of GSH after reaction with Ellman's reagent (5,5'-dithiobis-2-benzoic acid, DNTB) which is detectable at $412 \mathrm{~nm}$. Firstly, in the presence of nicotinamide adenine dinucleotide phosphate (NADPH), GSSG is reduced by glutathione reductase to GSH and then evaluated by the same reaction as mentioned above. A thiol scavenging reagent is used for the measurement of GSSG to avoid the oxidation of GSH during sample collection and preanalytical preparation. This is a key factor preventing an overestimation of GSSG, because even small amounts of GSH undergoing oxidation simply lead to a great increase of GSSG afterwards. The highest amounts of glutathione are present in erythrocytes, therefore, we recalculated the glutathione concentration also to the concentration of $\mathrm{Hb}$ in blood. The concentration of GSH, $\mathrm{GSH} / \mathrm{GSSG}$ ratio, T-GSH/Hb, GSSG/Hb and $\mathrm{GSH} / \mathrm{Hb}$ was assessed by calculation.

Haemoglobin concentration was evaluated by the spectrophotometric haemoglobincyanide method (Drabkin and Austin 1935) with the use of Spekol 11 (Carl Zeiss AG, Germany).

Biochemical parameters were assessed by automatic analyser Indiko - Clinical Chemistry Analyser, type 863 (Thermo Fischer Scientific, Waltham, USA). All indices were measured by standardized laboratory methods. We used the following sets for measurement of individual indices provided by Biovendor - Laboratory Medicine a.s., Brno, Czech Republic: TP ( ${ }^{\mathrm{L} T o t a l}$ Protein [biuret] Cat. No. 12751), Alb ( ${ }^{\mathrm{L}}$ Albumin, Cat. No. 10001), U ( ${ }^{\mathrm{L} U r e a, ~ C a t . ~}$ No. 12702), Glu ( ${ }^{\mathrm{L} G l u c o s e}$ GOD-POD, Cat. No. 11601), Crea ( ${ }^{\mathrm{L} C r e a t i n i n e J a f f e ́, ~ C a t . ~ N o . ~ 10917), ~ C h o l ~(~}{ }^{\mathrm{L}}$ Cholesterol, Cat. No. 10851), TAG ( ${ }^{\mathrm{L} T r i a c y l g l y c e r o l s ~ m o n o, ~ C a t . ~ N o . ~ 12805), ~ A L T ~(~}{ }^{\mathrm{L} A L T}$, Cat. No. 10452), AST ( ${ }^{\mathrm{L} A S T}$, Cat. No. 10352), ALP ( ${ }^{\mathrm{L} A L P}$, Cat. No. 10252), GGT ('GGT, Cat. No. 11502), Tbil ('Total Bilirubin, Cat. No. 10552), $\mathrm{P}$ (LInorganicPhosporus, Cat. No. 11354), Ca ( ${ }^{\mathrm{L} C a l c i u m A r z e n a z o}$ III, Cat. No. 12101), Cl ( ${ }^{\mathrm{L} C h l o r i d e s, ~ C a t . ~ N o . ~}$ 11951).

\section{Statistical evaluation}

The basic statistical parameters for all variables were calculated and are shown in tables. The normality of the data distribution was assessed using Kolmogorov-Smirnov test. As the data of glutathione concentrations and most of the other evaluated biochemical parameters were not normally distributed, non-parametric tests were used for the statistical evaluation. Differences between the four groups according to age and feeding were tested by Kruskal-Walis test and Dunn's post hoc test. The effect of sex was evaluated by Mann-Whitney test. The relationships between T-GSH, GSSG, GSH, T-GSH/Hb, GSSG/Hb, GSH/Hb, selected biochemical parameters and age with feeding were evaluated by regression analysis and Spearman's correlation coefficient was presented. We assessed the level of significance at $P \leq 0.05$. The statistical analysis was performed by UNISTAT Version 6.0 (Unistat Ltd, London, United Kingdom).

\section{Blood glutathione concentration}

\section{Results}

We found rather high variability of glutathione concentrations in whole blood of calves. The coefficient of variability was $26.6 \%$ for T-GSH, $85.3 \%$ for GSSG, $24.3 \%$ for GSH and $157.4 \%$ for the GSH/GSSG ratio. The results for the whole dataset are shown in 
Table 5. The distribution of the data is shown in Figs 1 (A,B,C) for T-GSH, GSSG, and GSH, respectively. The highest Spearman correlation coefficient was found between GSSG in whole blood and values recalculated to $\mathrm{Hb}(\mathrm{r}=0.972, P \leq 0.01)$; lower but also significant correlations were found for T-GSH $(\mathrm{r}=0.677, P \leq 0.01)$ and GSH $(\mathrm{r}=0.572$, $P \leq 0.05)$. The relationships are shown in Fig. $2(\mathrm{~A}, \mathrm{~B}, \mathrm{C})$.

Table 5. The concentration of total glutathione (T-GSH), oxidised glutathione (GSSG) and reduced glutathione $(\mathrm{GSH})$ in whole blood and values recalculated to the concentration of haemoglobin $(\mathrm{Hb})$ in calves $(\mathrm{n}=117)$.

\begin{tabular}{|c|c|c|c|c|c|}
\hline & Mean & Median & SEM & Minimum & Maximum \\
\hline T-GSH $(\mu \mathrm{mol} / 1)$ & 789.1 & 766.0 & 19.4 & 424.0 & 1491.0 \\
\hline GSSG $(\mu \mathrm{mol} / 1)$ & 54.2 & 39.0 & 4.3 & 1.0 & 171.0 \\
\hline $\mathrm{GSH}(\mu \mathrm{mol} / \mathrm{l})$ & 680.6 & 647.0 & 15.3 & 247.0 & 1161.0 \\
\hline GSH/GSSG & 41.1 & 17.7 & 5.9 & 2.0 & 454.0 \\
\hline T-GSH $(\mu \mathrm{mol} / \mathrm{g} \mathrm{Hb})$ & 5.07 & 4.38 & 0.19 & 2.03 & 12.03 \\
\hline GSSG $(\mu \mathrm{mol} / \mathrm{g} \mathrm{Hb})$ & 0.360 & 0.232 & 0.032 & 0.009 & 1.591 \\
\hline $\mathrm{GSH}(\mu \mathrm{mol} / \mathrm{g} \mathrm{Hb})$ & 4.35 & 3.94 & 0.14 & 1.18 & 9.08 \\
\hline
\end{tabular}

Table 6. The concentration (mean \pm SEM) of total glutathione (T-GSH), reduced glutathione (GSH), oxidized glutathione (GSSG) and the GSH/GSSG ratio in individual groups according the age with type of feeding.

\begin{tabular}{lccccr}
\hline & $\begin{array}{c}\text { Group CM } \\
(\mathrm{n}=20)\end{array}$ & $\begin{array}{c}\text { Group M } \\
(\mathrm{n}=39)\end{array}$ & $\begin{array}{c}\text { Group MR } \\
(\mathrm{n}=29)\end{array}$ & $\begin{array}{c}\text { Group TMR } \\
(\mathrm{n}=29)\end{array}$ & $P$-value \\
\hline T-GSH $(\mu \mathrm{mol} / \mathrm{l})$ & $923.5 \pm 65.7$ & $760.0 \pm 32.9$ & $724.0 \pm 34.4$ & $785 \pm 24.9$ & 0.101 \\
GSSG $(\mu \mathrm{mol} / \mathrm{l})$ & $79.5 \pm 9.3^{\mathrm{a}, \mathrm{b}}$ & $67.0 \pm 8.1^{\mathrm{cc}, \mathrm{dd}}$ & $28.0 \pm 7.4^{\mathrm{a}, \mathrm{cc}}$ & $24.0 \pm 4.6^{\mathrm{b}, \mathrm{dd}}$ & $<0.001$ \\
$\mathrm{GSH}(\mu \mathrm{mol} / \mathrm{l})$ & $771.5 \pm 54.7$ & $604.0 \pm 25.2$ & $654.0 \pm 26.5$ & $675.0 \pm 42.5$ & 0.216 \\
GSH/GSSG & $8.32 \pm 1.6^{\mathrm{a}, \mathrm{b}}$ & $11.0 \pm 9.4^{\mathrm{cc}, \mathrm{dd}}$ & $23.0 \pm 16.9^{\mathrm{a}, \mathrm{cc}}$ & $27.7 \pm 10.3^{\mathrm{b}, \mathrm{dd}}$ & $<0.001$ \\
\hline
\end{tabular}

SEM $=$ standard error of the mean, ${ }^{\text {a }} P \leq 0.05$, aa $P \leq 0.01$

The same letters in one raw show statistical significant difference between groups; Group CM: age 1-5 days, fed with colostrum and transition milk; Group M: age 6-14 days, fed with fresh milk; Group MR: age 15 days to 2.5 months, fed with milk replacer; Group TMR: age 4-6 months, fed with total mixed ration

Glutathione concentration in relationship to feeding, together with age and sex of animals

We compared the effect of age with different types of feeding - colostrum and transition milk nutrition, native milk feeding, milk replacer fed by an automatic feeder, and total mixed ration on glutathione levels. The results are shown in Table 6. A significant effect of age and type of feeding was detected only for GSSG and the GSH/GSSG ratio. Calves receiving colostrum or native milk had significantly higher concentration of GSSG in comparison with calves receiving milk replacer and calves after weaning.

Similarly, a significant effect of age was proven on the concentration of GSSG $(\mathrm{r}=-0.482$; $P<0.001)$ and the GSH/GSSG ratio $(\mathrm{r}=0.476 ; P<0.001)$. The relationships between age and T-GSH were very weak $(\mathrm{r}=-0.192 ; P \leq 0.05)$ and no significant correlation was found with GSH. The concentrations of individual forms of glutathione in whole blood in relationship to the age of animals are shown in Fig. 3 (A, B, C). These figures show that young animals had much higher variability in glutathione concentrations, mainly GSSG, compared to the older animals. 
Table 7. Selected biochemical indices and their correlation with total glutathione (T-GSH), reduced glutathione $(\mathrm{GSH})$, oxidized glutathione (GSSG) and the GSH/GSSG ratio in the complete dataset $(\mathrm{n}=117)$.

\begin{tabular}{lrrrrrrr}
\hline & Mean & Median & SEM & \multicolumn{3}{c}{ Spearman correlation coefficient } \\
\cline { 6 - 8 } & & & & T-GSH & GSSG & GSH & GSH/GSSG \\
\hline Albumin $(\mathrm{g} / \mathrm{l})$ & 33.88 & 33.70 & 0.32 & -0.079 & $-0.316^{* *}$ & 0.003 & 0.136 \\
Total protein $(\mathrm{g} / \mathrm{l})$ & 54.78 & 53.70 & 0.77 & -0.046 & -0.157 & -0.030 & 0.119 \\
Urea $(\mathrm{mmol} / \mathrm{l})$ & 4.04 & 3.80 & 0.23 & -0.040 & -0.035 & -0.043 & 0.053 \\
Creatinine $(\mu \mathrm{mol} / \mathrm{l})$ & 90.32 & 85.00 & 2.80 & $0.266^{*}$ & $0.442^{* *}$ & 0.129 & $-0.428^{* *}$ \\
Total bilirubin $(\mu \mathrm{mol} / \mathrm{l})$ & 6.09 & 4.60 & 0.66 & 0.151 & 0.089 & 0.215 & -0.057 \\
Cholesterol $(\mathrm{mmol} / \mathrm{l})$ & 2.94 & 3.00 & 0.10 & -0.094 & $-0.208^{*}$ & -0.094 & $0.198^{*}$ \\
Triacylglycerols $(\mathrm{mmol} / \mathrm{l})$ & 0.30 & 0.22 & 0.02 & 0.010 & 0.118 & -0.077 & -0.106 \\
AST $(\mu \mathrm{kat} / \mathrm{l})$ & 1.21 & 1.11 & 0.04 & -0.158 & $-0.329^{* *}$ & 0.017 & $0.299^{*}$ \\
ALT $(\mu \mathrm{kat} / \mathrm{l})$ & 0.34 & 0.28 & 0.03 & -0.197 & $-0.323^{*}$ & -0.041 & 0.276 \\
GGT $(\mu \mathrm{kat} / \mathrm{l})$ & 1.77 & 0.38 & 0.55 & 0.078 & $0.276^{*}$ & -0.042 & $-0.311^{* *}$ \\
ALP $(\mu \mathrm{kat} / \mathrm{l})$ & 4.20 & 3.73 & 0.23 & -0.038 & -0.029 & -0.045 & 0.001 \\
Calcium $(\mathrm{mmol} / \mathrm{l})$ & 2.67 & 2.68 & 0.02 & 0.149 & $0.215^{*}$ & 0.020 & $-0.207^{*}$ \\
Phosphate $(\mathrm{mmol} / \mathrm{l})$ & 3.16 & 3.07 & 0.07 & -0.136 & -0.091 & -0.159 & 0.084 \\
Chloride $(\mathrm{mmol} / \mathrm{l})$ & 97.04 & 97.50 & 0.41 & $-0.185^{*}$ & -0.141 & -0.167 & 0.131 \\
Hemoglobin $(\mathrm{g} / \mathrm{l})$ & 167.0 & 178.0 & 3.63 & 0.009 & -0.088 & 0.092 & 0.080 \\
\hline SEM = standard & & & & & & &
\end{tabular}

$\mathrm{SEM}=$ standard error of the mean; $* P \leq 0.05, * * P \leq 0.01$

The effect of sex was evaluated only in calves that were fed colostrum and transition milk or native milk, due to the breeding system, because older bulls were kept at a different place. In total, 32 heifers and 27 bulls were evaluated for this purpose. The concentrations (mean \pm SEM) of T-GSH (843.4 \pm 41.7 vs. $816.48 \pm 49.3 \mu \mathrm{mol} / 1)$, GSSG $(72.9 \pm 8.4$ vs. $77.0 \pm 9.6 \mu \mathrm{mol} / \mathrm{l})$, GSH $(697.6 \pm 32.5$ vs. $662.6 \pm 39.5 \mu \mathrm{mol} / \mathrm{l})$ and the GSH/GSSG ratio $(25.9 \pm 9.51$ vs. $28.9 \pm 8.53)$ did not differ significantly in heifers and bulls, respectively.

The relationships between glutathione and biochemical parameters

The basic statistical characteristics of selected biochemical parameters of the whole data set $(n=117)$ together with Spearman correlation coefficients to individual forms of glutathione are shown in Table 7. The relationships between glutathione and biochemical parameters were mostly weak. The T-GSH concentration correlates significantly only with the concentrations of creatinine and chlorides. The closest relationships to metabolic indices were shown by GSSG, which significantly correlated with Alb, Crea, Chol, AST, ALT, GGT and Ca. The GSH/GSSG ratio showed significant relationships with the same indices except Alb and ALT.

\section{Discussion}

Literature describing glutathione in cattle is scarce and we found rather high variability between the results. No reference values exist for the T-GSH, GSH or GSSG forms in cattle. Kaneko et al. (1997) mentioned GSH levels of $2890 \pm 460 \mu \mathrm{mol} / 1$ in cattle. Nevertheless, no information is available concerning the methods, breed, age etc.

Some papers evaluating the concentration of glutathione in blood were published in recent years, using similar spectrophotometrical method with Ellman's reagent as a fluorescent detectable product but the authors evaluated only T-GSH. Bozukluhan et al. (2017) found the mean values of $76.30 \pm 3.61 \mathrm{mg} / \mathrm{dl}$ (recalculated $2482 \pm 118 \mu \mathrm{mol} / \mathrm{l}$ ) in whole blood of healthy cows. They considered the GSSG levels negligible. Similarly 


\section{Total glutathione (T-GSH)}

A

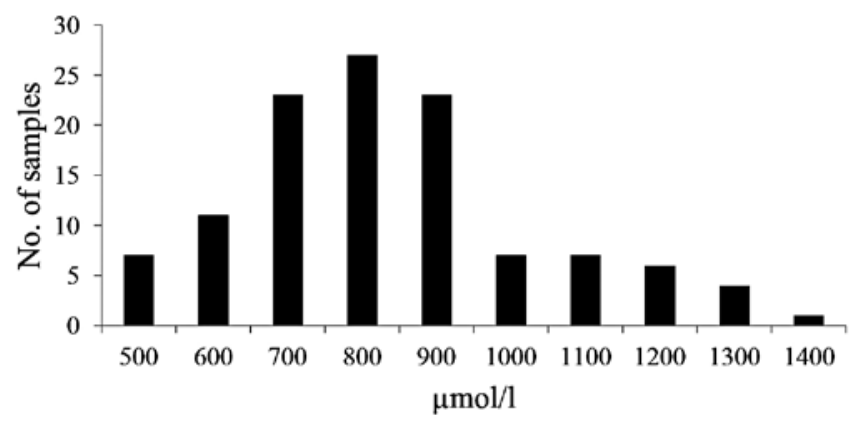

Oxidized glutathione (GSSG)

B

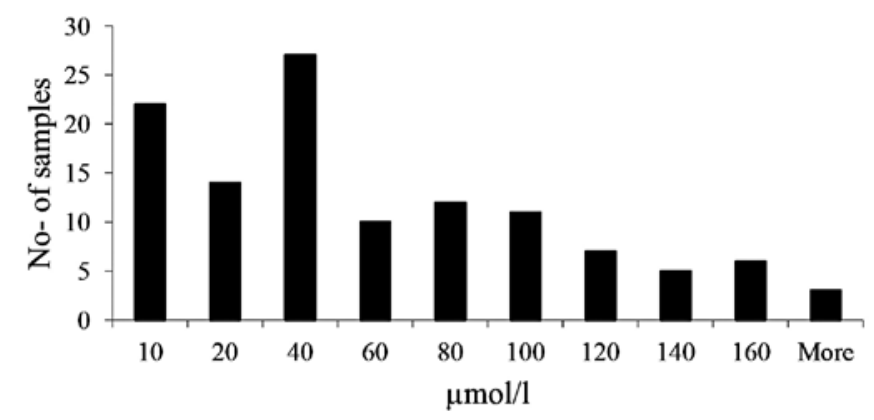

Reduced glutathione (GSH)

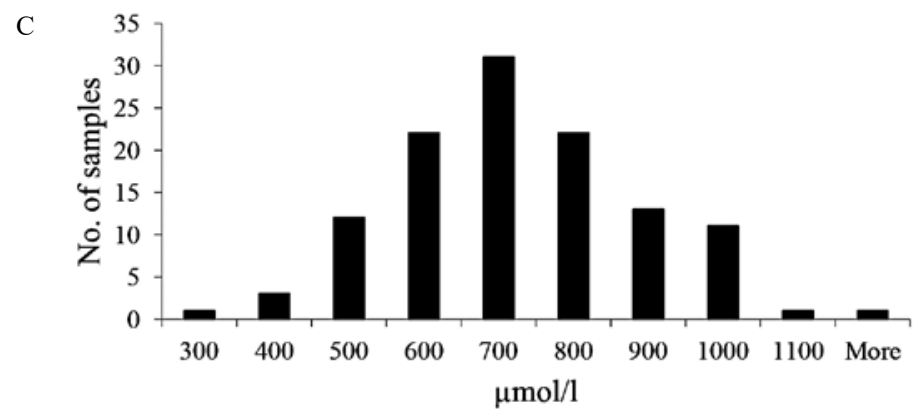

Fig. 1. Frequency distributions of concentrations of individual forms of glutathione in whole blood of calves (Atotal glutathione (T-GSH), B - oxidized glutathione (GSSG), C - reduced glutathione (GSH))

Uzlu et al. (2016) measured $63.43 \pm 2.92 \mathrm{mg} / \mathrm{dl}$ (recalculated $2064 \pm 95 \mu \mathrm{mol} / \mathrm{l}$ ) in whole blood of bulls. These values are higher than ours, which can be due to a different category, breed or age of animals but most likely due to the procedure used for the assessment. An essential and limiting factor in the evaluation of glutathione is stabilizing the autooxidation of GSH, which can lead to overestimation of T-GSH but most importantly, overestimation of GSSG by a large amount in samples. The authors do not distinguish between T-GSH and GSH, as in most papers the GSSG levels are described as so low they can be considered 


\section{Total glutathione (T-GSH)}
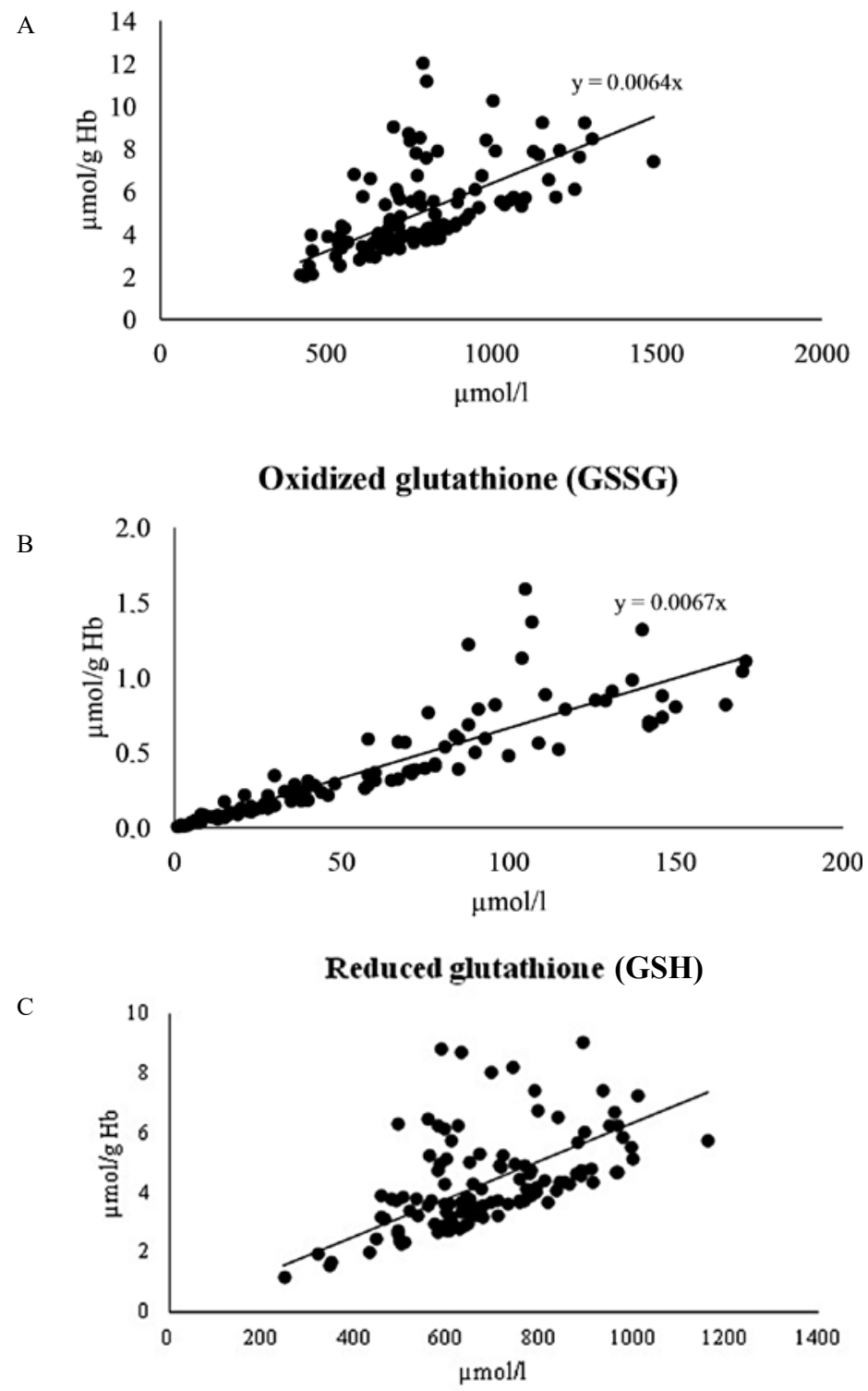

Fig. 2. The relationship between the concentrations of individual forms of glutathione and their values recalculated to haemoglobin $(\mathrm{Hb})$; (A - total glutathione (T-GSH), B - oxidized glutathione (GSSG), C - reduced glutathione (GSH))

negligible. Nevertheless, the GSH/GSSG ratio can differ enormously. The GSH redox couple in mammalian cells ranges between $1-10 \mathrm{mmol} / \mathrm{l}$. In a resting cell the molar GSH/ GSSG ratio exceeds 100:1, whereas in various models of oxidative stress, this ratio has been reported to decrease to values between 10:1 and even 1:1 (Chai et al. 1994). For the 


\section{Total glutathione (T-GSH)}
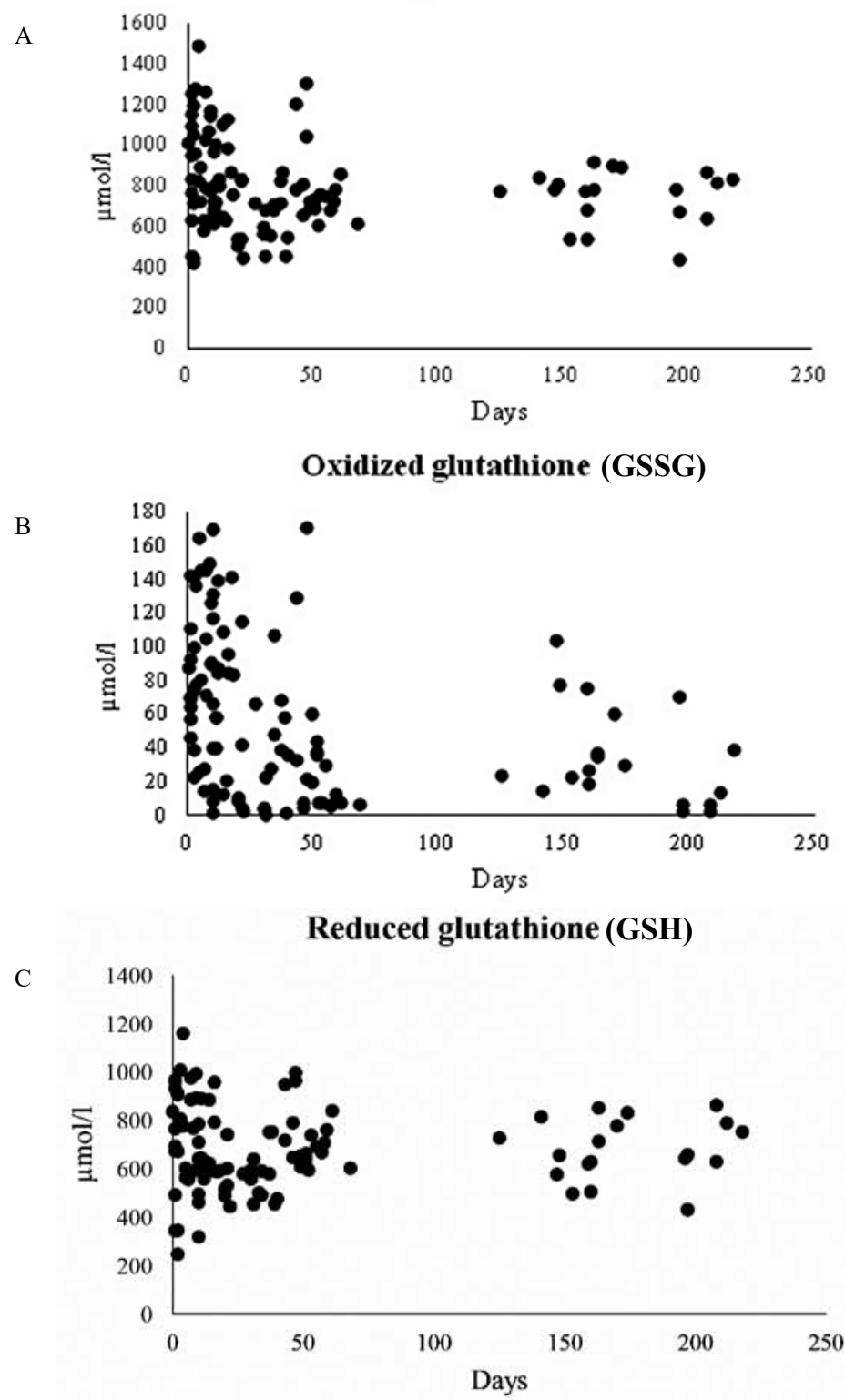

Figure 3. The effect of age of calves on the concentration of individual form of glutathione in whole blood (A total glutathione (T-GSH), B - oxidized glutathione (GSSG), C - reduced glutathione (GSH))

proper evaluation and interpretation it is a must to detect both forms of glutathione redox system and not even reduced or total GSH.

The comparison of results is difficult mainly due to the fact that no standard method for glutathione evaluation was established and just a few experiments measuring glutathione 
exist in literature. These papers are incomparable because of the different conditions set in the experiment, inconsistent type of sample, its withdrawal, processing, and last but not least, the measuring method.

High levels of stress in high yielding dairy cows leads to glutathione ratio discrepancies, followed by subclinical disorders and consecutive clinical manifestation of diseases, decreased milk yield, obstacles in reproduction and bad herd rentability. Sharma et al. (2011) measured GSH levels in blood of dairy cows. They divided the animals according to the phase of pregnancy and days of lactation. They observed quite wide ranges of GSH levels in blood in cows 4 weeks before calving and 4 weeks in the lactation period. The mean concentration was $94 \pm 21 \mu \mathrm{mol} / 1$ in the first group and $234 \pm 37 \mu \mathrm{mol} / \mathrm{l}$ in the second. They found the growth of glutathione levels to go hand in hand with lipid peroxidation and negative correlation with glutathione peroxidase (GPx) activity. They explained their findings as an increased oxidative stress during the time of parturition which can lead to periparturient disorders (Waller 2000; Gitto et al. 2002).

Earlier in vivo and in vitro studies support the theory that oxidative stress during the transition period, particularly during parturition, may be a major underlying cause of inflammatory and immune dysfunction in dairy cattle (Aitken et al. 2009).

The levels of individual forms of glutathione detected in our experiment are similar to the values reported for human blood. Michelet et al. (1995) measured the mean values in whole human blood $941 \pm 155 \mu \mathrm{mol} / \mathrm{l}$ for T-GSH and $849 \pm 63 \mu \mathrm{mol} / \mathrm{l}$ for GSH; plasmatic GSH level was $3.39 \pm 1.04 \mu \mathrm{mol} / 1$ in adults. In children, the values of T-GSH and GSH in whole blood were found to be $872 \pm 157 \mu \mathrm{mol} / \mathrm{l}$ and $814 \pm 171$ $\mu \mathrm{mol} / \mathrm{l}$, respectively. Mean plasma GSH concentration was determined to be $3.57 \pm$ $0.74 \mu \mathrm{mol} / \mathrm{l}$. The highest amount of glutathione is present in erythrocytes and thus the glutathione concentration in whole blood is much higher than in plasma. Intracellular and blood concentrations of GSH are in millimolar range, whereas the plasma concentration is in the micromolar range and accounts for approximately $0.4 \%$ of total blood GSH (Michelet et al. 1995). Serru et al. (2001) reported the following levels in whole human blood (expressed as mean \pm SD) $486 \pm 85 \mu \mathrm{mol} / 1$ for GSH, $68 \pm 26$ $\mu \mathrm{mol} / 1$ for GSSG, and $553 \pm 90 \mu \mathrm{mol} / 1$ for T-GSH. Giustarini et al. (2003) measured the mean levels of $1384 \mu \mathrm{mol} / 1,1378 \pm 96 \mu \mathrm{mol} / 1$, and $3.21 \pm 0.87 \mu \mathrm{mol} / 1$ for T-GSH, GSH, and GSSG in whole blood, respectively.

In order to determine the effect of the erythrocyte count and considering the objectivity of glutathione levels in whole blood, we recalculated the concentration of individual forms of glutathione to haemoglobin concentration. We found a very close correlation of GSSG in whole blood recalculated to $\mathrm{Hb}$ concentration. T-GSH and GSH showed weaker but also significant correlations. None of the glutathione forms correlated with the concentration of $\mathrm{Hb}$ in blood.

According to Meister (1988) GSH serves as a storage and transport form of cysteine moieties and cysteine is rate-limiting substrate for de novo GSH synthesis (Iwasaki et al. 2009). Once GSH is formed by the red blood cell it retains inside for its needs (Meister and Anderson 1983). Reduced glutathione can occur as a solo molecule inside the cell, but due to its instable-SH group it routinely bounds other molecules such as proteins, peptides and aminoacids. On the other hand, GSSG stays stable and unreactive until undergoing the reduction by glutathione reductase activity, which ensures its regeneration to GSH. Moreover, inside the cell GSH is found not only in cytoplasm but also in mitochondria and ribosomes. Bounding of other moieties and inter-organelle transport can therefore explain the weaker correlation between GSH and its recalculated values to $\mathrm{Hb}$.

The evaluation of the effect of the daily ration shows that the GSSG concentration was significantly higher in calves fed with colostrum and transition milk or native milk. Similar but not significant, the T-GSH concentration was also higher in these two groups. 
Based on our results, the age and type of feeding go hand in hand and cannot be evaluated separately. Nevertheless, similar evaluation was not found in available literature. If focused on the dietary factors, the concentration of glutathione could be affected by the intake of essential aminoacids; this is because adequate intake of sulphur amino acids methionine and cysteine is important for glutathione synthesis. Cellular GSH homeostasis is maintained through the de novo synthesis from the precursor methionine and cysteine, regeneration from its oxidized form and uptake of extracellular intact GSH. Cysteine availability and local GSH concentration have a direct influence on epithelial cell proliferation and survival and are inversely proportional to cellular differentiation state. Methionine availability and its conversion to cysteine and GSH via transsulphuration may be important for maintenance of normal intestinal and hepatic cell proliferation and survival (Burrin and Stoll 2005). Milk is an important source of essential aminoacids and the content of methionine is relatively high $(28 \mathrm{~g} / \mathrm{kg}$ protein, $1.02 \mathrm{~g} / \mathrm{l} \mathrm{milk})$ and the content of cysteine is lower ( $7 \mathrm{~g} / \mathrm{kg}$ protein, $0.26 \mathrm{~g} / \mathrm{l} \mathrm{milk)}$ (Jensen 2005). The concentration of methionine could be lower in milk replacer compared to native milk or colostrum due to the addition of vegetable protein.

Regarding the effect of the diet, the impact of copper and selenium supplementation on the concentration of GSH in blood of calves was published. Neto et al. (2014) found an increase of the GSSG concentration in the liver with the selenium, copper and selenium/ copper treatment. Values in control animals with no addition of selenium or copper were around $2500 \mu \mathrm{mol} / \mathrm{kg}$ and $90 \mu \mathrm{mol} / \mathrm{kg}$ of liver tissue in GSH and GSSG, respectively. The biggest deterioration of GSH was observed in a group fed with selenium and copper supplements simultaneously at concentrations around $1800 \mu \mathrm{mol} / \mathrm{kg}$ for GSH and 200 $\mu \mathrm{mol} / \mathrm{kg}$ for GSSG. Similarly Correa et al. (2012) reported a decrease in GSH and cholesterol concentrations when feeding copper supplements. In copper supplemented Nelore beef cattle GSH and GSSG varied on average from 1310 to $1580 \mu \mathrm{mol} / \mathrm{kg}$ and 14 to $18 \mu \mathrm{mol} / \mathrm{kg}$ of liver tissue, respectively, depending on the source and amount of added copper. In the control group with no addition of copper, the mean GSH and GSSG were $1840 \mu \mathrm{mol} / \mathrm{kg}$ and $12 \mu \mathrm{mol} / \mathrm{kg}$ of liver tissue, respectively.

The effect of age on the concentration of glutathione in blood of cattle has not been described in any available literature. From our dataset it is clear that higher variability in all types of glutathione is typical for young animals, which corresponds to higher sensitivity of young animals to metabolic or infectious diseases due to an immature immune system and probably also regulation of metabolism. Young animals are at higher risk of developing oxidative stress. The negative effect of different diseases is described in literature. Studies which were performed in recent years evaluated the glutathione concentration during some infectious diseases. The decrease of glutathione in whole blood was found by Bozuklukhan et al. (2017) in cattle with brucellosis (2202 $\pm 51 \mu \mathrm{mol} / \mathrm{l})$ compared to healthy individuals $(2482 \pm 118 \mu \mathrm{mol} / \mathrm{l})$ and by Uzlu et al. (2016) in bulls with the foot and mouth disease $(812 \pm 75$ in diseased bulls vs. $2064 \pm 95 \mu \mathrm{mol} / \mathrm{l}$ in the healthy control). El-Mandrawy and Alam (2018) proved severe decrease of GSH in serum of cows affected with the lumpy skin disease (mean $130 \pm 0.16 \mu \mathrm{mol} / 1$ in affected vs. $358 \pm$ $0.29 \mu \mathrm{mol} / \mathrm{l}$ in healthy animals). Generally, in diseased animals GSH tends to decrease as a response to increasing oxidative stress. During the course of disease reduced glutathione diminishes, and we did not find values for GSSG in affected animals. The results show that diseased animals can restore GSH levels while recovering from the disease (Bozukluhan et al. 2017; El-Mandrawy and Alam 2018; Uzlu et al. 2016). Kirbas et al. (2014) measured GSH values similar to ours. They detected GSH in healthy Akkaraman sheep and those suffering from acute rumen lactic acidosis. The levels in serum were $560 \pm 122 \mu \mathrm{mol} / 1$ and $339 \pm 160 \mu \mathrm{mol} / \mathrm{l}$ in healthy and affected animals, respectively. A case study conducted by Talukder et al. (2014) monitored GSH in a dairy cow with an 
ovarian follicular cyst. The recycling method was used for the determination of GSH in plasma. The levels ranged from 2.5 to $3 \mu \mathrm{mol} / 1$.

The evaluation of metabolic profile and glutathione concentration show the relationships between some blood indices and glutathione. Positive significant correlation was found between creatinine and GSSG or T-GSH. The concentration of creatinine in blood reflects the quantity of muscles, thus we can suppose that also the concentration of glutathione is in some relationship to muscle metabolism. Beside this we found negative relationships of GSSG to albumin, cholesterol, liver enzymes (AST, ALT), which show possible effect of liver disturbances on the concentration of GSSG. Nevertheless all correlations between individual forms of glutathione and metabolic indices were weak probably due to the fact that we examined only animals without any clinical sign of diseases. For more detailed evaluation of the relationship between metabolism and glutathione, further studies on animals suffering from some metabolic disturbances need to be performed.

This was a pilot study showing some factors that influenced the concentration of different forms of glutathione in whole blood of calves without clinical signs of any disease. Next studies should involve calves suffering from different metabolic or infectious diseases.

\section{References}

Aitken SL, Karcher EL, Rezamand P, Gandy CJ, Vandehaar MJ, Capuco AV, Sordillo LM 2009: Evaluation of antioxidant and proinflammatory gene expression in bovine mammary tissue during the transition period. J Dairy Sci. 92: 589-598

Bodor R, Nečasová A, Pechová A, Masár M 2018: Capillary Isotachophoresis determination of trace oxidized glutathione in blood. HJIC 46: 13-17

Bozukluhan K, Merhan O, Celebi O, Buyuk F, Ogun M, Gokce G 2017: Levels of certain biochemical and oxidative stress parameters in cattle with Brucellosis. J Hellenic Vet Med Soc 68: 285-290

Burrin DG, Stoll B 2005: Splanchnic protein and amino acid metabolism in growing animals. In: Burrin DG, Mersmann HJ (Ed.): Biology of Metabolism in Growing Animals, Elsevier, Amsterdam, pp. 126-157

Chai YC, Hendrich S, Thomas JA 1994: Protein S-thiolation in hepatocytes stimulated by t-butyl hydroperoxide, menadione, and neutrophils. Arch Biochem Biophys310: 264-272

Correa LB, Zanetti MA, Del Claro GR, Pires de Melo M, Rosa AF, Netto AS, 2012: Effect of supplementation of two sources and two levels of copper on lipid metabolism in Nellore beef cattle, Meat Science 91: 466-471

Drabkin DL, Austin JH 1935: Spectrophotometric studies II. Preparations from washed Blood cells; nitric oxide hemoglobin and sulfhemoglobin. J Biol Chem112: 51

El-Mandrawy SAM, Alam RTM 2018: Hematological, biochemical and oxidative stress studies of lumpy skin disease virus infection in cattle. J Appl Anim Res 46: 1073-1077

Gitto E, Reiter RJ, Karbownik M, Tan DX, Gitto P, Barberi S, Barberi I 2002: Causes of oxidative stress in the pre- and perinatal period. Biol Neonate 81:146-157

Giustarini D, Dalle-Donne I, Colombo R, Milzani A, Rossi R 2003: An improved HPLC Measurement for GSH and GSSG in Human Blood. Free Rad Biol Med 35: 1365-1372

Iwasaki Y, Saito Y, Nakano Y, Mochizuki K, Sakata O, Ito R, Saito K, Nakazawa H 2009: Chromatographic and mass spectrometric analysis of glutathione in biological samples. J Chromatogr B Analyt Technol Biomed Life Sci 877: 3309-3317

Jensen G 1995: Handbook of Milk Composition, Academic press, London, 919 p.

Kaneko J, Harvey JW, Bruss ML 1997: Clinical Biochemistry of Domestic Animals, Academic Press, Fifth Edition, London, 932 p.

Kirbas A, Apaydin B, Baydar E, Kandemir FM 2014: Status of lipid peroxidation and some antioxidants in sheep with acute ruminal lactic acidosis. Medycyna weterynaryjna 70: 357-361

Meister A., Anderson ME 1983: Glutathione. Annu Rev Biochem 52:711-760

Meister A 1988: Glutathione metabolism and its selective modification. J Biol Chem 263: 17206-17208

Michelet F, Gueguen R, Leroy P, Wellman M, Nicolas A, Siest G 1995: Blood and plasma glutathione measured in healthy subjects by HPLC: relation to sex, aging, biological variables, and life habits. Clin Chem 41: 15091517

Netto AS, Zanetti MA, Del Claro GR, Pires de Melo M, Vilela FG, Correa LB 2014: Effects of copper and selenium supplementation on performance and lipid metabolism in confined Rangus bulls, Asian-Australas J Anim Sci 27: 488-494

Rossi R, Milzani A, Dalle-Donne I, Giustarini D, Lusini L, Colombo R, Di Simplicito P 2002: Blood glutathione disulfide: In vivo factor or in vitro artifact? Clin Chem 48: 742-753

Serru V, Baudin B, Ziegler F, David JP, Cals MJ, Vaubourdolle M, Mario N 2001: Quantification of reduced and oxidized glutathione in whole blood samples by capillary electrophoresis. Clin Chem 47: 1321-1324 
Sharma N, Singh NK, Singh OP, Pandey V, Verma PK 2011: Oxidative stress and antioxidant status during transition period in dairy cows. Asian-Australas J Anim Sci 24: 479-484

Talukder S, Ingenhoff L, Kerrisk K, Celi P 2014: Plasma oxidative stress biomarkers and progesterone profiles in a dairy cow diagnosed with an ovarian follicular cyst. The Vet Quart 34: 113-117

Uzlu E, Karapehlivan M, Erdogan H, Kiziltepe S, Erkilic EE, Deveci HA, Gokce E, Kaya I, Citil M 2016: Serum and saliva acid and oxidative stress parameters changes in bulls with foot and mouth disease. Kafkas Univ Vet Fak Derg 22: 321-325

Waller KP 2000: Mammary gland immunology around parturition. Influence of stress, nutrition and genetics. Adv Exp Med Biol 480: 231-245 